\title{
CONF-911111--39
}

$\mathrm{ANL} / \mathrm{CP}--73951$

DE92 009519

MATERIALS ISSUES IN THE DESIGN OF THE ITER FIRST WALL, BLANKET, AND DIVERTOR*

R.F. Mattas, D.L. Smith

Fusion Power Program, Argonne National Laboratory

Argonne, Illinois 60439 USA

\section{C.H. Wu}

The NET Team, Max-Planck Institute fur Plasmaphysik Garching, Germany

T. Koroda

Japan Atomic Energy Research Institute Ibaraki-ken 311-02, Japan

G. Shatalov

Kurchatov Institute of Atomic Energy Moscow 123182, USSR

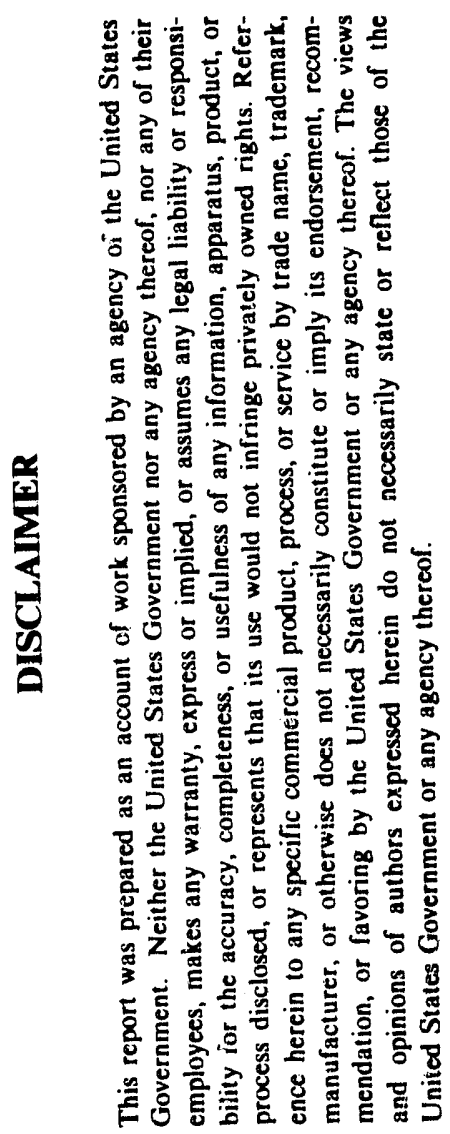

* Work supported by the Office of Fusion Energy, U.S. Department of Energy under Contract Number W-31-109-Eng-38.

Paper presented at the Fifth International Conference on Fusion Reactor Materials, Sheraton Sand Key Resort, Clearwater, FL, November 17-22, 1991. 
MATERIALS ISSUES IN THE DESIGN OF THE ITER FIRST WALL, BLANKET, AND DIVERTOR* R.E. Mattas, D.L. Smith Argonne National Laboratory, Argonne, IL USA

C.H. Wu

The NET Team, Max-Planck Institute fur Plasmaphysik, Garching, Germany

T. Koroda

Japan Atomic Energy Research Institute, Ibaraki-ken 311-02, Japan

G. Shatalov

Kurchatov Institute of Atomic Energy, Mossow 123182, USSR

\section{Abstract}

During the ITER conceptual design study, a pronerty data base was assembled, the key issues were identified, and a comprehensive R\&D plan was formulated to resolve these issues. The desired properties of candidate ITER divertor, first wall, and blanket materials are briefly reviewed, and the major materials issues are presented. Estimates of the influence of materials properties on the performance limits of the first wall, blanket, and divertor are presented.

The first option blanket for ITER incorporates a ceramic breeder for tritium production along with a neutron multiplier. The structural material is SA 316 stainless steel, and the entire blanket/shield assembly is cooled by low temperature, low pressure water. The ceramic breeders being considered are lithium oxide and ternary lithium ceramics $\left(\mathrm{Li}_{2} \mathrm{ZrO}_{3}, \mathrm{LiAlO} \mathrm{O}_{2}\right.$, and $\left.\mathrm{LiSiO}_{4}\right)$, and beryllium has been selected as the neutron multiplier. Since elevated temperatires $\left(T>400^{\circ} \mathrm{C}\right)$ are required for the release of tritium, the ceramic

* Work supported by the U.S. Department of Energy, Office of Fusion Energy, under contract No. W-31-109-Eng-38: 
breeder in ITER will operate in an environment similar to advanced power reactors. The primary issues associated with the ceramic breeder are tritium retention and release, chemical stability, and radiation effects on the physical properties. In contrast, the SA 315 structure will operate at temperatures $<350^{\circ} \mathrm{C}$. The major issues associated with the stainless steel are the effects of neutron irradiation on the mechanical properties and compatibility with the coolant, particularly stress corrosion cracking effects. An alternate blanket design utilizes PbLi as a breeder/multiplier, and it is also cooled by low temperature, low pressure water. The major issues for this design are associated with compatibility, tritium containment/recovery, and the need to melt the eutectic at frequent intervals to release the tritium.

The divertor for ITER is composed of a plasma facing material which is bonded to a structural heat sink. The plasma facing materials being considered are various forms of graphite, tungsten, and beryllium. The issues associated with these materials are their capability to accommc Jate high heat loads, sputtering erosion and redeposition, retention of tritium, response during disruptions, and radiation effects on physical properties. The heat sink materials being considered are molybdenum, niobium, and copper alloys. The major issues for heat sink materials are their capability to accommodate high heat loads, radiation effects on ductility, and thermal fatigue and crack growth behavior. 


\section{Introduction}

During the ITER Conceptual Design Activity (CDA) a material property data base was assembled which was utilized as part of the design process to analyze operational performance and limitations.

Materials information was provided for blanket and PFC structural materials, plasma facing materials, ceramic breeders, beryllium, and insulators. This information was provided by a large number of experts from the EC, Japan, USSR, and U.S. This paper will briefly review the process by which the materials information was used during the CDA and then describe a few specific examples of how materials performance set, the operational limits of nuclear components. A complete review of all the materials data base for ITER is beyond the scope of this paper, and readers are encouraged to read Refs. 1-3 for additional details.

Materials input is an integral part of the ITER design process as indicated in Fig. 1. The overall goals and performance of the device were set by the ITER terms of reference which in turn lead to selection of design goals for the nuclear systems, e.g., tritium breeding requirements, lifetime fluence, operation temperature, etc. During the CDA a number of design options were proposed and each option was analyzed and evaluated utilizing the existing materials data base. Based upon tinese analyses, key issues for each option were identified and the leading designs were chosen. The key design issues were used to formulate the near-term materials R\&D requirements, and as new materials data became available it was used to refine the leading designs. Ultimately, this process led to the selection of first options for the $F W / B / S$ system and PFC system.

A number of design options were considered for the blanket and plasma facing components during the CDA. For the blanket, water-cooled ceramic 
breeders, water-cooled solid PbLi, Li-aqueous salt, and helium cooled ceramic breeder options were initially considered. The first design option selected for the blanket was the water-cooled ceramic breeder with the water-cooled PbLi option as the alternate. Safety considerations and limitations on available space for manifolding led to the selection of low-pressure, lowtemperature water as the coolant. Fabrication and R\&D developement requirements led to the selection of annealed austenitic stainless steel as the structural material. The ceramic breeder option also employs large amounts of beryllium as a neutron multiplier to enhance the tritium breeding ratio. The operating temperatures of the solid breeder were set in part by the need for rapid tritium release and recovery and the safety concerns with minimizing tritium inventory.

Plasma facing components design options are dependent mainly upon the choice for the plasma facing material. The desirable attributes of the plasma facing material are minimization of plasma impurities, the ability to accommodate high heat loads, and resistance to sputtering and disruption effects. The plasma edge conditions predicted for ITER led to the chcice of either very low $-Z$ ( $\mathrm{Be}, \mathrm{C})$ or high-Z materials ( $W, \mathrm{Ta}$ ) in order to minimize plasma impurity effects.

\section{2. $F W / B / S$ system considerations}

The blanket operating conditions are shown in Table 1 [1]. For these conditions, there are various desirable properties associated with the FW/B/S materials as shown in Table 2. In order to accommodate high surface heat loads on the first wall it is desirable to have favorable thermophysical properties. Over time, the effects of radiation and chemical environments tend to lead to embrittlement and cracking. At the relatively low 
temperatures of operation and fluence, it is not expected that radiation swelling will be significant. For ceramic breeders, the main issues are related to heat transfer and thermal stress capability, chemical compatibility, resistance to radiation damage and tritium release. Mechanical property effects are of reduced importance in ceramic breeders since they are not required to withstand structural loads. A key issue is the tritium release characteristics since it is important to maintain tritium inventory at a low level. The beryllium multiplier has similar desirable properties to the ceramic breeder. Although the rate of tritium production is much lower in beryllium, if it is not released the tritium inventory could reach $\mathrm{kg}$ quantities [1]. Hence, tritium release is also an important issue with beryllium.

\subsection{First wall structure}

Annealed austenitic stainless tell has been studied extensively for use in the fusion breeder reactor and advanced fusion systems. Although there is a large amount of information on radiation effects at $\mathrm{T}>400^{\circ} \mathrm{C}$, there is only limited information at the low temperatures of interest to ITER. In addition, there is very limited information on radiation effects at the higher He/dpa levels expected for fusion neutron damage. Recent data on changes in mechanical properties at low irradiated $T$ and high He/dpa ratios indicates a fairly rapid decrease in ductility as shown in Fig. 2 [4]. Somewhat surprisingly there is a indication that the embrittlement is more severe in the $200-350^{\circ} \mathrm{C}$ range than at $\mathrm{T}<100^{\circ} \mathrm{C}$. During normal operation, the loss of ductility should not pose a serious problem since the FW/B/S structure would be designed to operate in the elastic regime. During off-normal events, the loss of ductility poses a more serious issue, since the stress levels may 
exceed the yield stress possible resulting in plastic deformation and cracking. Loss of ductility therefore results and a reduced capability to accommodate off-normal events.

The reduction in ductility in the ITER first wall has been calculated, based upon the data from Rer. 4. The FLIP code was used to make the calculations [5]. The assumed ITER conditions are shown in Table 3. The results for the change in uniform elongation are shown in Fig. 3. During the Physics Phase the loss of ductility is inconsequential to operation, but, during the Technology Phase, the ductility could be significantly reduced. It is anticipated that operational experience will lead to improved control over the plasma burn and a reduced frequency of off-normal events hy the time the Technology Phase begins. However, there is an increasing probability of a cracking and failure during an off-normal event as the Technology Phase proceeds. Fission irradiation data also shows large increases in the yield and ultimate strength of SA316 SS as shown in Fig. 4 [2]. For the ITER conditions from Table 2 , it is predicted that the yield strength would increase from $200 \mathrm{MPa}$ to $700 \mathrm{MPa}$ over the ITER operating lifetime.

\subsection{Ceramic breeder}

The leading candidate ceramic breeders are $\mathrm{Li}_{2} \mathrm{O}, \mathrm{Li}_{4} \mathrm{SiO}_{4}, \mathrm{Li}_{2} \mathrm{ZrO}_{3}$, and $\mathrm{LiAlO}_{2}$. The data base for the properties of interest, indicated in Table 2, have been assembled, and a comparison of the materials is shown in Table 4. All materials appear to be potentially acceptable for use in ITER, but all materials exhibit some properties which are unattractive. In addition, some properties are not well understood at present, and therefore, additional R\&D is required to complete the database. Properties where more information is 
desired include tensile properties, tritium solubility and transport, and radiation creep.

An important issue for the ceramic breeder is the retention and release of tritium. The general approach used for recovering the tritium is to provide porosity in the ceramic breeder (70-80\% TD) so the bred tritium can diffuse a short distance through the bulk to a pore surface and be released into the pore. A helium flow stream is passed through the blanket where it will pick up the tritium that has migrated through the open porosity to the helium purge channels and then removed from the blanket to the tritium processing system. The rate of release depends upon the behavior of the tritium within the solid breeder and on the surface release characteristics. Important materials properties involved in retention and release include tritium solubility in the ceramic breeder, bulk diffusion coefficients, surface recombination of tritium, and surface adsorption/desorption characteristics. The behavior of each of these phenomena is strongly dependent upon the temperature of operation. In order to minimize tritium inventory and to maximize tritium release, the ceramic breeder should operate in a restricted temperature range.

At low temperatures, where bulk diffusion is slow, tritium inventories are expected to increase, and at high temperatures, inventories will also increase due to increased solubility of tritium. Detailed models of tritium behavior in ceramic breeders have been formulated and compared with reactor test data [6]. The amount of data on tritium inventory is limited, since inventory determination must be done after the in-reactor tests. As shown in Fig. 5, there is a significant amount of scatter in the comparison of model prediction and experiment, but in most cases the model over-predicts the inventory [6]. 
The predicted level of tritium inventory in ITER has been calculated based upon these models, as shown in Fig. 6 [7]. For $\mathrm{Li}_{2} \mathrm{O}$ at $\mathrm{TC} \sim 400^{\circ} \mathrm{C}$ there is a sharp use in inventory predicted due to increased bulk diffusion time and precipitation of $\mathrm{LiOH}$. At $\mathrm{T}>\sim 600^{\circ} \mathrm{C}$, tritium solubility in $\mathrm{Li}_{2} \mathrm{O}$ increases, and at temperatures in-between these extremes, inventory is determined primarily by surface adsorption/desorption. For a $1 \mathrm{MW} / \mathrm{m}^{2}$ wall loading $\left(400^{\circ} \mathrm{C}<\mathrm{T}<\sim 515^{\circ} \mathrm{C}\right)$, the predicted tritium inventory for the entire blanket is $10-100 \mathrm{~g}$ which is well within safety guidelines, and is below predicted levels for graphite used as a plasma facing material [3].

\subsection{Plasma facing components}

Plasma facing components are probably exposed to the most severe environment in ITER. Not only are they exposed to a high flux of neutrons like the blanket materials, but they are also exposed directly to the plasma resulting in high surface heat fluxes and sputtering erosion. They must be able to survive the damage from disruptions. The desirable properties for plasma facing materials is shown in Table 5. The materials being considered include graphite (pyrolytic, carbon fiber composites), beryllium (plasma sprayed), tungsten (plasma sprayed) as plasma facing materials, and copper alloys, niobium alloys, and molybdenum alloys as the heat sink structural material. There is no one material that exhibits all the desirable attributes. For the Physics Phase of operation graphite is the leading candidate with beryllium as the alternate plasma facing material. For the Technology Phase, tungsten is the leading candidate, again with beryllium as the alternate plasma facing material.

As an example of the use of materials data in establishing the performance limits of plasma facing materials the influence of chemical 
sputtering effects on the temperature limits for graphite will be described. Graphite has a unique response to sputtering in that the sputtering increases with temperature. As shown in Fig. 7 for $H$ and $D$ on $C$, enhanced chemical erosion occurs in the temperature range from $\sim 600-1000 \mathrm{~K}$ and is the results of the formation of hydrocarbon species [8]. At high temperature there is an increase in sputtering due to radiation enhanced sublimation. the erosion yield for $1 \mathrm{keV} \mathrm{H}$ and $\mathrm{D}$ on carbon exceeds unity at $2000 \mathrm{~K}$. Self-sputtering is also a. factor in establishing performance limits. As shown in Fig. 8 for $\mathrm{C}^{+}$on $\mathrm{C}$, radiation enhanced sublimation occurs at $\mathrm{T}>\sim 1000 \mathrm{~K}$ [2]. In this case, however, the erosion yield exceeds unity at $\sim 1200-1500 \mathrm{~K}$ depending upon the carbon ion energy. Self-sputtering is a limiting factor in PFC operation, since runaway sputtering leading to plasma shutdown is predicted when the self-sputtering coefficient exceeds unity.

This data has been incorporated into a comprehensive modelling code, called REDEP [9] that has been used to establish the operating temperatures of graphite on the divertor plate. The code considers sputtering, as well as the edge particle behavior, e.g., energy distribution, angle of incidence, sheath potential, plasma density, etc. Sputtered particles are analyzed to determine when they are ionized in the plasma edge and then return to the plate to resputter and/or redeposit on the surface. Figure 9 shows the maximum operating surface energy as a function of plasma edge temperature [3]. The limit is based upon self-sputtering reaching unity. The general trend is for the allowable surface temperature to decrease as the plasma edge temperature increases. For the reference case, the plasma edge temperature must be below $\sim 30 \mathrm{eV}$ in order to allow a graphite temperature $\geq 2000^{\circ} \mathrm{C}$. As the edge temperature increases, the allowable temperature decreases sharply so that when the edge temperature exceeds $\sim 180 \mathrm{eV}$, graphite is no longer predicted to 
predicted to be viable for the divertor. The dashed lines indicated how uncertainties in the plasma physics can influence the allowable temperature.

Even when physical sputtering is eliminated from the calculation, there is a temperature limit of $\sim 1300^{\circ} \mathrm{C}$ due to radiation enhanced sublimation. For the ITER reference case, the surface temperature limit has been set at 1000$1200^{\circ} \mathrm{C} \mathrm{[3].} \mathrm{This} \mathrm{rather} \mathrm{modest} \mathrm{temperature} \mathrm{limits} \mathrm{the} \mathrm{allowable} \mathrm{thickness} \mathrm{of}$ the graphite and hence the expected lifetime of the divertor plate.

\subsection{Conclusions}

The materials data base assembled during the ITER CDA has been integrated into the tesign process. The property data has been used to establish the fundamental limits of the nuclear systems performance and to determine key issues that require further investigation. The examples given above are indicative of the methods employed in analyzing system performance. The key materials issues have been used to establish R\&D needs for the near future.

\section{Acknowledgements}

The authors gratefully acknowledge the contributions of all the individuals that contributed to the ITER Materials Data Base. They are: M. Akiba, M. Araki, T. Ando, D. Baldwin, R. Bastasz, R. Behrisch,

U. Bergenlid, W. Bogaerts, H. Bolt, M. Brossa, A. Bruggeman, M. Budd,

S. Casadio, R. Causey, F. Clinard, S. Cohen, R. Conrad, M. Devries, W. Dienst, D. Duquette, J. Elliot, M. Eto, A. Fischer, T. Flament, F. Garner, D. Gelles, P. Gierszewski, Y. Gohar, A.A. Grigorian, A. Haasz, R. Heidinger,

A. Hishinuma, E. Hodgson, G. Hollenberg, A. Hull, A. Ibarra, V.A. Ignatov, H. Ise, C. Johnson, R. Jones, V.A. Azakov, V.P. Karklina, T. Kassner, D. Kirk, A. Kohyama, A. Krauss, T. Kuroda, H. Kwast, T. Lechtenberg, V. Levy, 
G. Longhurst, B. Loomis, G. Martin, D. Mazey, L. Miller, V.Z. Nepomnyaschchiy,

T. Oku, G. Pells, Y.G. Prolofiev, A.S. Pokorsky, G.L. Saksagansky,

V. Zemliankin, V.G. Markov. H. Nickel, B.V. Petroy, J. Roth, N. Roux,

A. Rowxliffe, G. Santarini, P. Schiller, M. Seki, N. Sekimura, G.A. Sernyaev,

B. Singh, D. Slagle, M. Smith, Yu.N. Sokursky, S.I. Sorokin, J. Stephens,

A. Tavassoli, V.N. Tebus, Yu.M. Trapeznikov, S.I. Turchin, H. Ullmaier,

J. Van Der Laan, W. Vandermeulen, B. Ban Der Schaaf, M. Victoria, E. Vietzke,

N.K. Vinogradova, H. Watanabe, K. Wilson, H. Wollenberger, A.P. Zakharov,

H. Werle, J. Whitley, and S. Zinkle.

\section{References}

[1] D.L. Smith, et. al., "ITER Blanket Shield and Materials Data Base: Part A (ITER Blanket and Shield)," ITER Documentation Series, No. 29, International Atomic Energy Agency, Vienna (1991).

[2] D.L. Smith, et. al, "ITER Blanket Shield and Materials Data Base: Part B (Materials Data Base)," ITER Documentation Series, No. 29, International Atomic Energy Agency, Vienna (1991).

[3] T. Kuroda, et. al., "ITER Plasma Facing Components," ITER Documentation Series, No. 30, International Atomic Energy Agency, Vienna (1991).

[4] A.F. Rowcliffe, A. Hishinuma, M.L. Grossbeck, S. Jitsuhawa, "Radiation Effects at Fusion Reactor He:dpa Ratios: Overview of U.S./Japan Spectrally Tailored Experiments," J. Nucl. Mater., 179-181 (1991) 125125.

[5] R.F. Mattas, "Fusion Component Lifetime Analysis," Argonne National Laboratory report, ANL/EPP/TM-160 (1982).

[6] M.C. Billone, H. Attaya, Y. Gohar, J. Kopasz, C.E. Johnson, and S.W. Tam, "Modelling of Tritium Behavior in Ceramic Breeder and Beryllium Multiplier Materials," this conference.

[7] D.L. Smith et al., "Tritium Breeding Blanket," Fusion Technology 19, No. 3, Part 2B (1991) 1424.

[8] J. Roth, J. Bohdansky, and K.L. Wilson, "Erosion of Carbon Due to Bombardment with Energetic Ions at Temperatures up to $2000 \mathrm{~K}$, " J. Nucl Mater., $111 \& 112$ (1982) 775-780.

[9] J.N. Brooks, Nuc. Tech./Fusion 4 (1983) 33. 
Table 1. Blanket Operating Conditions and Design Guidelines

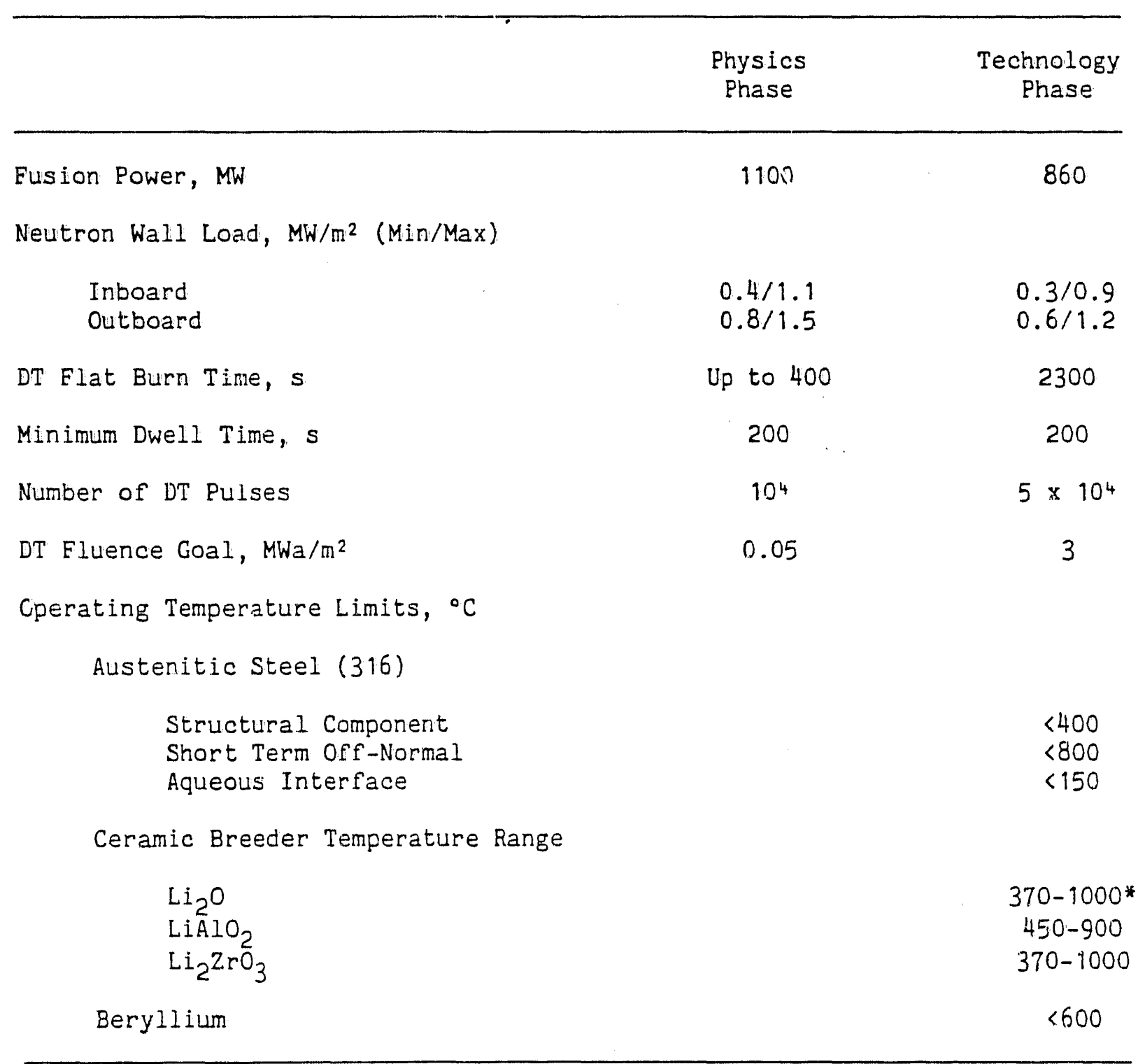

* Special attention should be given to avoid mass transport above $800^{\circ} \mathrm{C}$. 
Table 2. Desirable Properties of Blanket Materials

\section{Structural Materials}

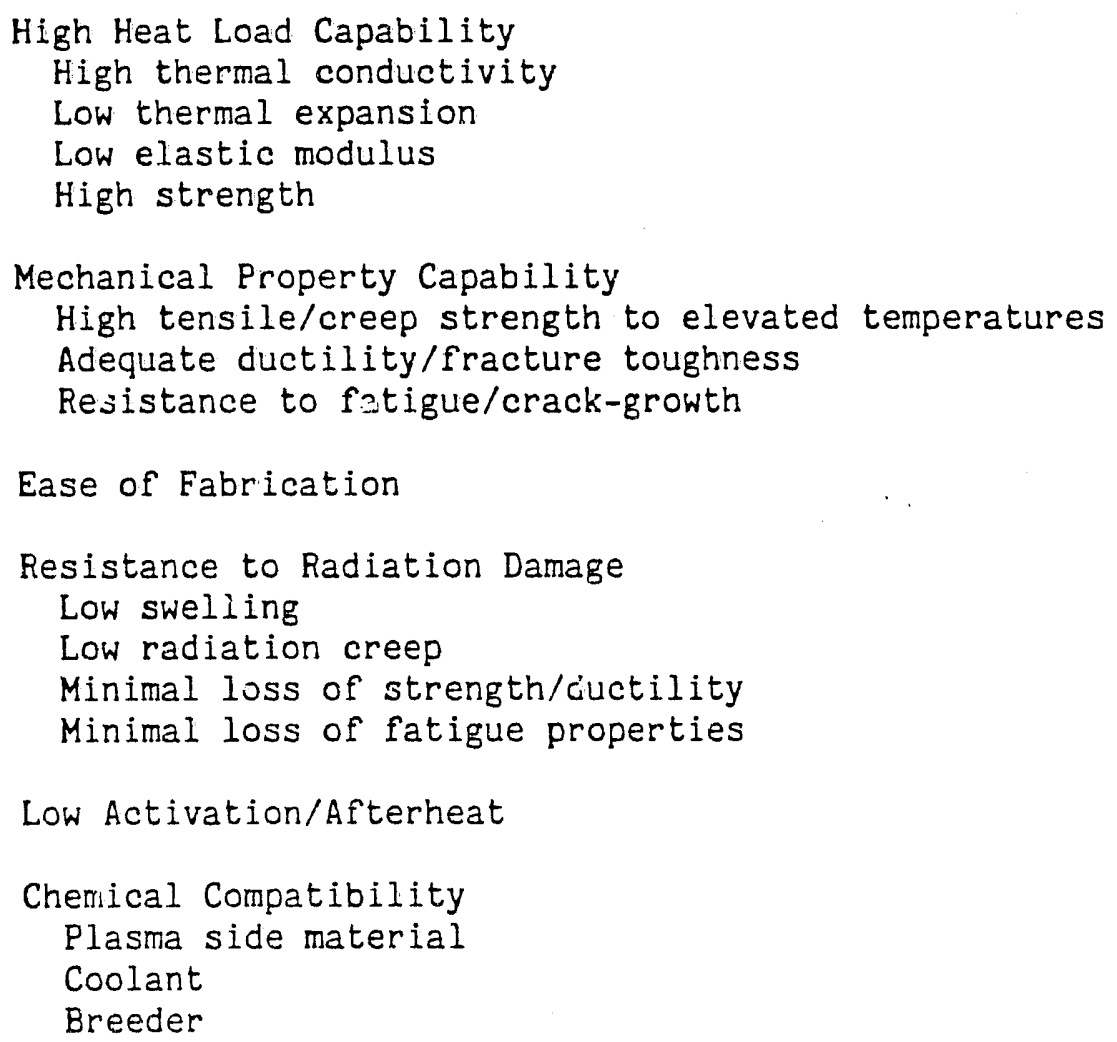

\section{Ceramic Breeders and Beryllium}

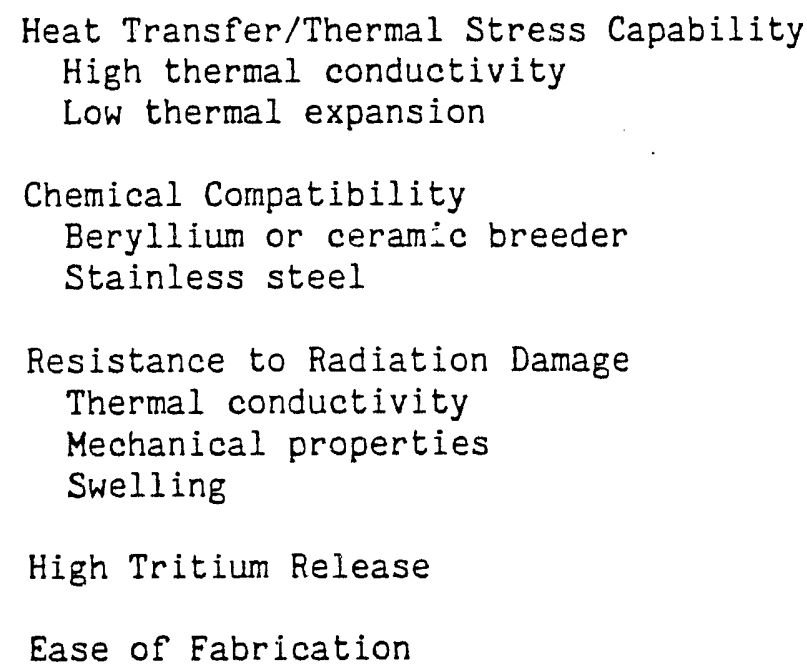


Table 3. ITER Conditions Assumed for FLIP Code Predictions

\section{Code Predictions}

First Wall Material

Annealed Type 316 Stainless Steel

First Wall Thickness

$4 \mathrm{~mm}$ - Plasma Facing Layer

$4 \mathrm{~mm}$ - Blanket Facing Layer

Surface Heat Flux

$0.5 \mathrm{MW} / \mathrm{m}^{2}$ - Plasma Facing Layer

$0.3 \mathrm{MW} / \mathrm{m}^{2}$ - Blanket Facing Layer

Neutron Wall Loading

$1.0 \mathrm{MW} / \mathrm{m}^{2}$

Burn Cycle Time

400 s - Physics Phase

2000 s - Technology Phase

Total Fluence

$0.07 \mathrm{MW} \cdot \mathrm{y} / \mathrm{m}^{2}$ - Physics Phase

$1.0 \mathrm{MW} \cdot \mathrm{y} / \mathrm{m}^{2}$ - Technology Phase 


\section{Non-Structural Materials}

Ceramic Breeder Materials

- Baseline physical properties

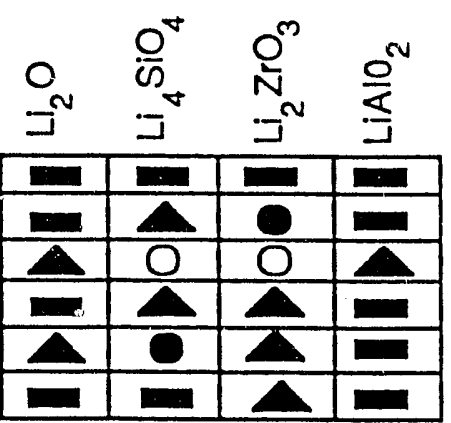

- Baseline mechanical properties

- Elastic modulus

- Poisson's ratio

- Fraclure strength

- Tensile

- Compressive

- Bending strength

- Creep properties

\begin{tabular}{|l|l|l|l|l|}
\cline { 2 - 6 } & $\Delta$ & $\Delta$ & $\Delta$ & $\mathbf{A}$ \\
\hline & $\Delta$ & $\Delta$ & 0 & $\Delta$ \\
\hline & 0 & 0 & 0 & $\Delta$ \\
\hline sth & 0 & $\Delta$ & 0 & $\Delta$ \\
\hline
\end{tabular}

- Chemical stability/compatibility

- Composition/purity

- Stability

- Vapor pressure/transport

- Compatibility

- Water

- Beryllium

- SS

- Tritium solubility/transport

- Tritium solubility

- Tritium diffusivity

- Adsorption/desorption properties

\begin{tabular}{|c|c|c|c|c|}
\hline & & & & \\
\hline & $=$ & & & \pm \\
\hline & $E$ & 0 & 0 & 0 \\
\hline & & 4 & & \\
\hline & & 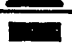 & $\bar{A}$ & \\
\hline & 0 & $\bar{E}$ & $\vec{A}$ & \\
\hline
\end{tabular}

Radiation effects

- Physical properties

- Swelling

- Creep

- Tritium trapping/transport

- Helium trapping/transport

- Fracture properties 
Table 5. Desirable Properties of Plasma Facing Materials

\author{
Low Sputtering Erosion Rates \\ Low Impact of Surface Sputtering on Plasma Performance \\ High Thermal Shock/Heat-Load Capability \\ High thermal conductivity \\ Low thermal expansion \\ Low elastic modulus \\ High fracture stress \\ High Stopping Power for Runaway Electrons \\ Ease of Fabrication \\ Compatibility with Hydrogen Isotopes \\ Low chemical interaction rate \\ Low trapping probability \\ Low permeability \\ Low Activation/Afterheat \\ Resistance to Fatigue Damage \\ Resistance to Radiation Damage \\ Physical properties \\ Mechanical properties
}




\section{Figure Captions}

Fig. 1. Flow diagram showing how materials property data is integrated into the ITER design process.

Fig. 2. Uniform elongation of annealed austenitic stainless steel following low temperature irradiation to $\sim 8$ dpa with $\mathrm{He}(\mathrm{appm}) / \mathrm{dpa} \sim 14$.

Fig. 3. Predicted decrease in the uniform elongation of the ITER first wall. (Physics Phase is -5000 cycles).

Fig. 4. Increase in yield strength and ultimate tensile strength of annealed austenitic stainless steel following irradiation.

Fig. 5. Comparison of model predictions and data for tritium inventory in irradiated $\mathrm{Li}_{2} \mathrm{O}$.

Fig. 6. Predicted tritium inventory in the ITER driver blanket with $\mathrm{Li}_{2} \mathrm{O}$.

Fig. 7. Erosion yield on graphite during $1 \mathrm{keV} \mathrm{H,} \mathrm{D} \mathrm{bombardment} \mathrm{as} \mathrm{a} \mathrm{function}$ of temperature.

Fig. 8. Erosion yield of graphite during $\mathrm{C}^{+}$bombardment at $0.1,0.3$, and 13 keV.

Fig. 9. Maximum allowable graphite surface temperature on the ITER divertor plate as a function of plasma edge temperature. 
Fig. 1

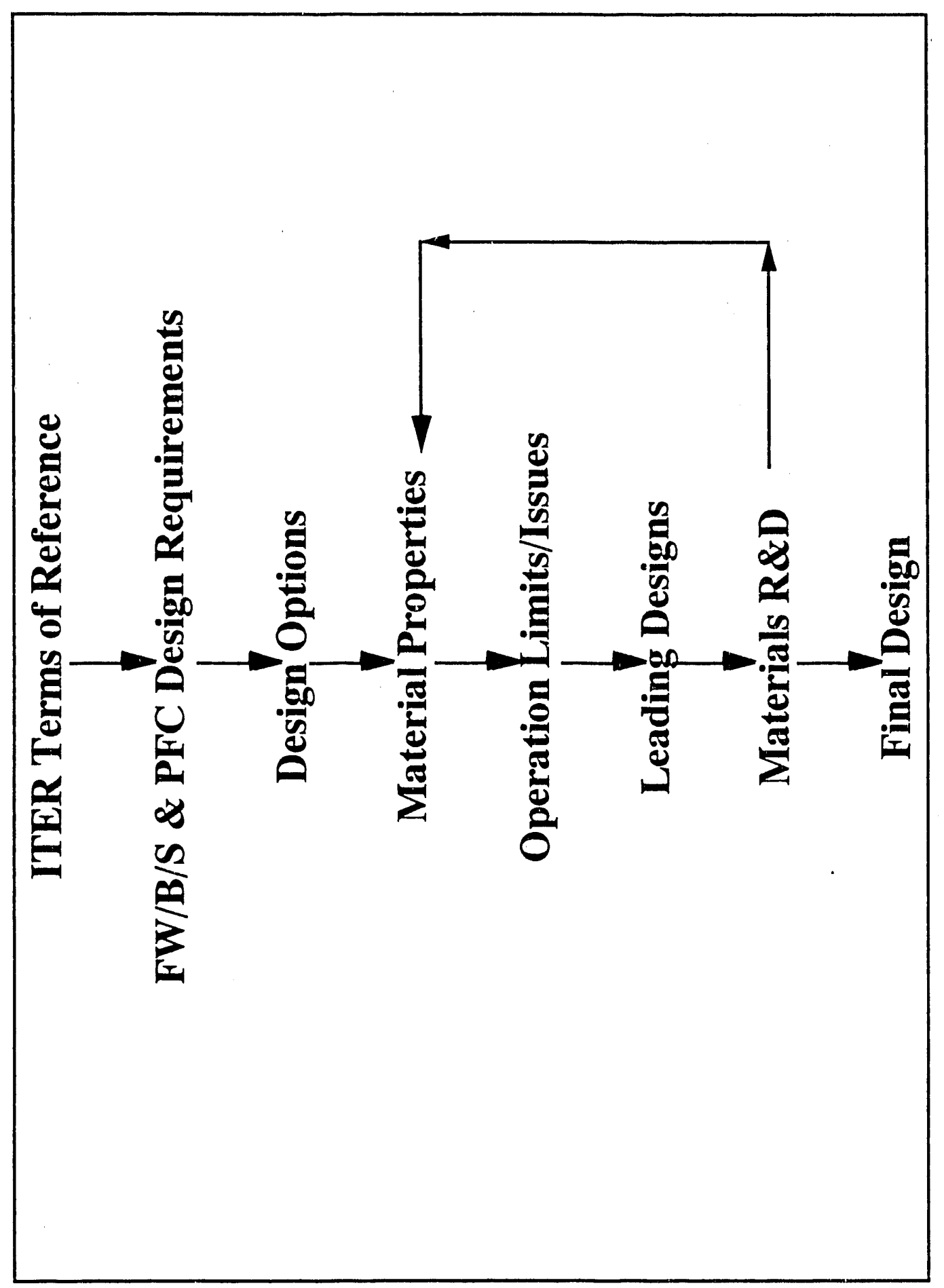


-Fig. 2

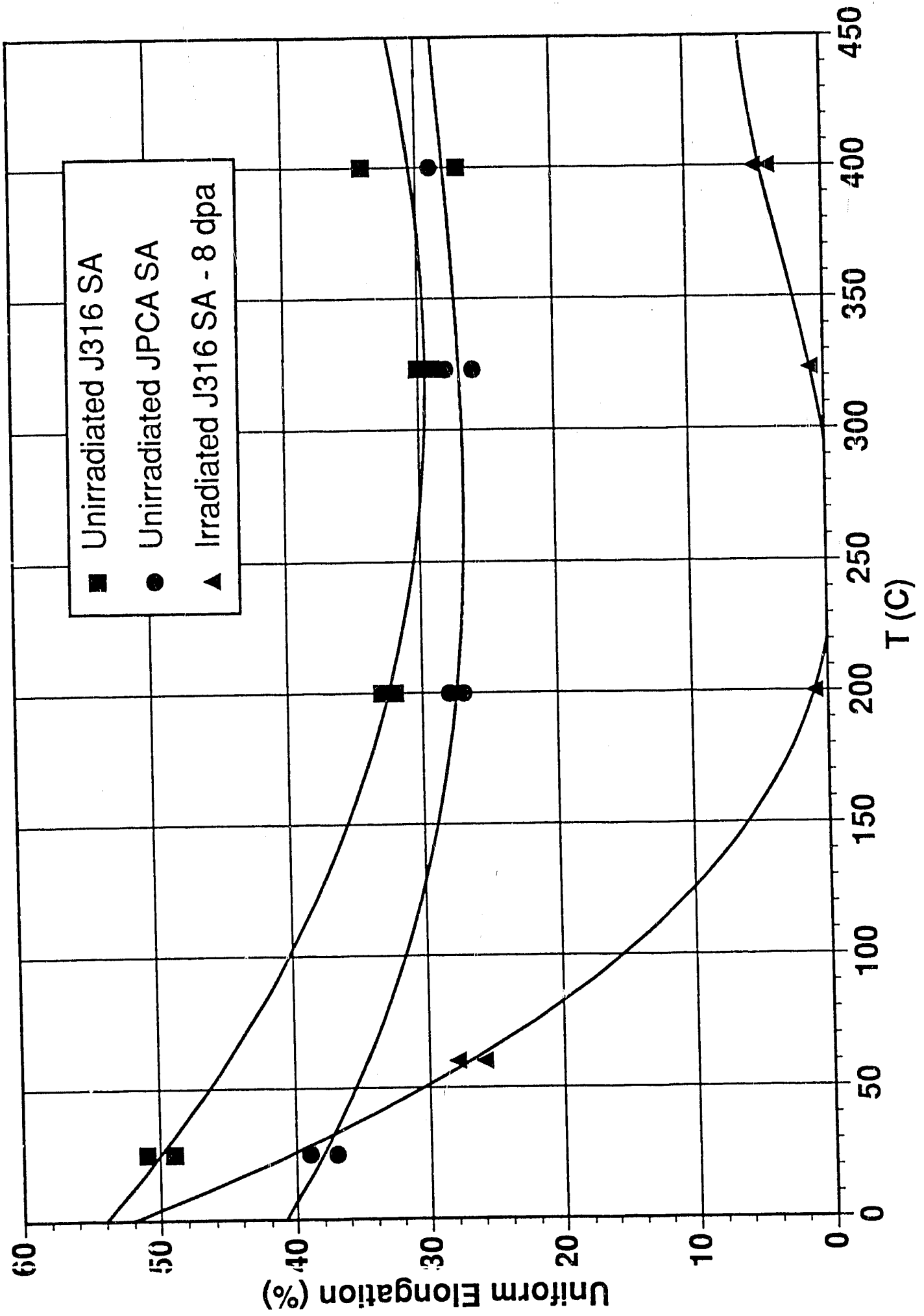


Fig. 3

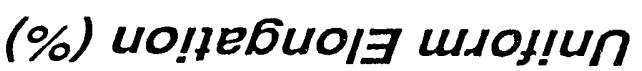

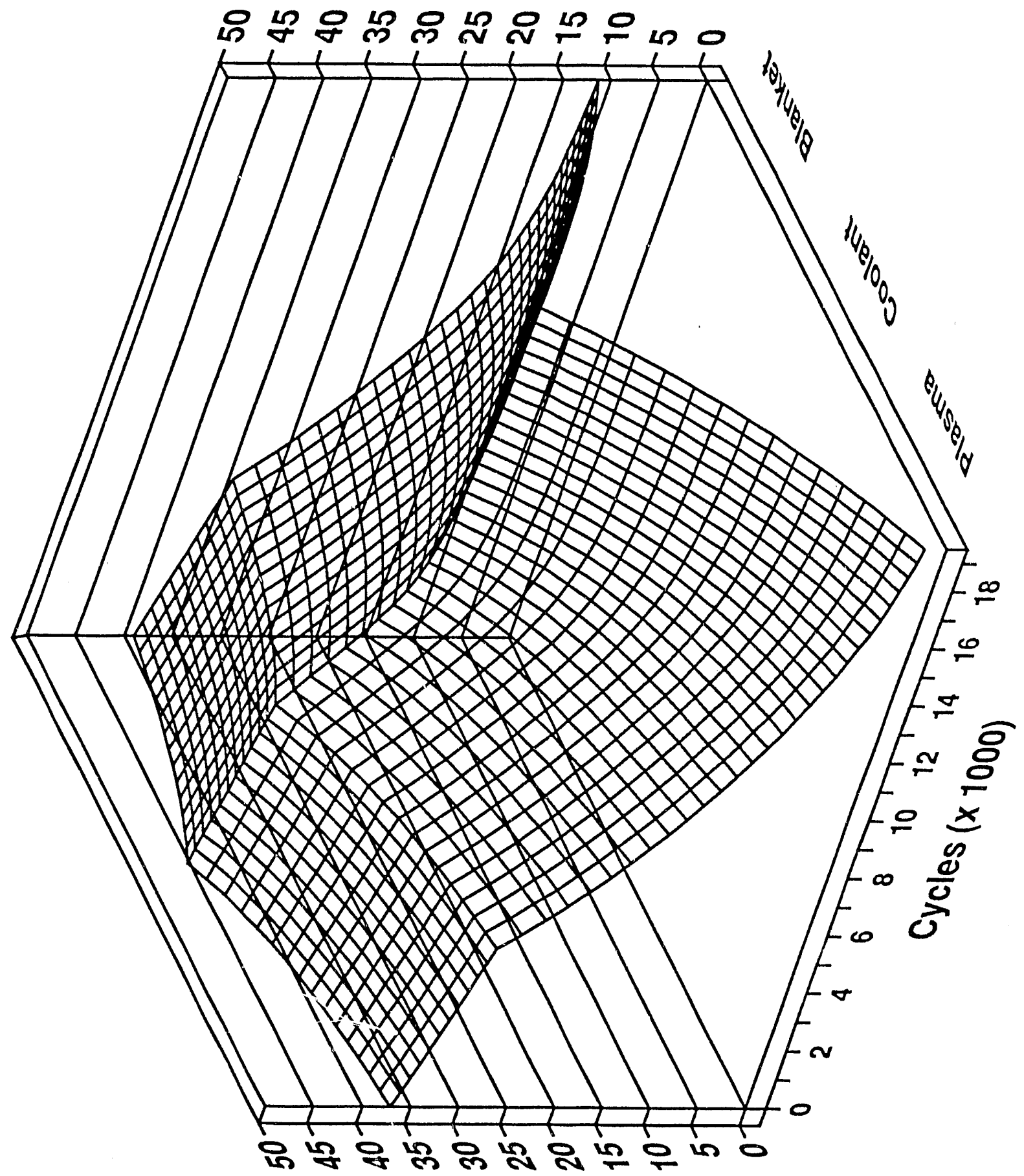


Fig. 4
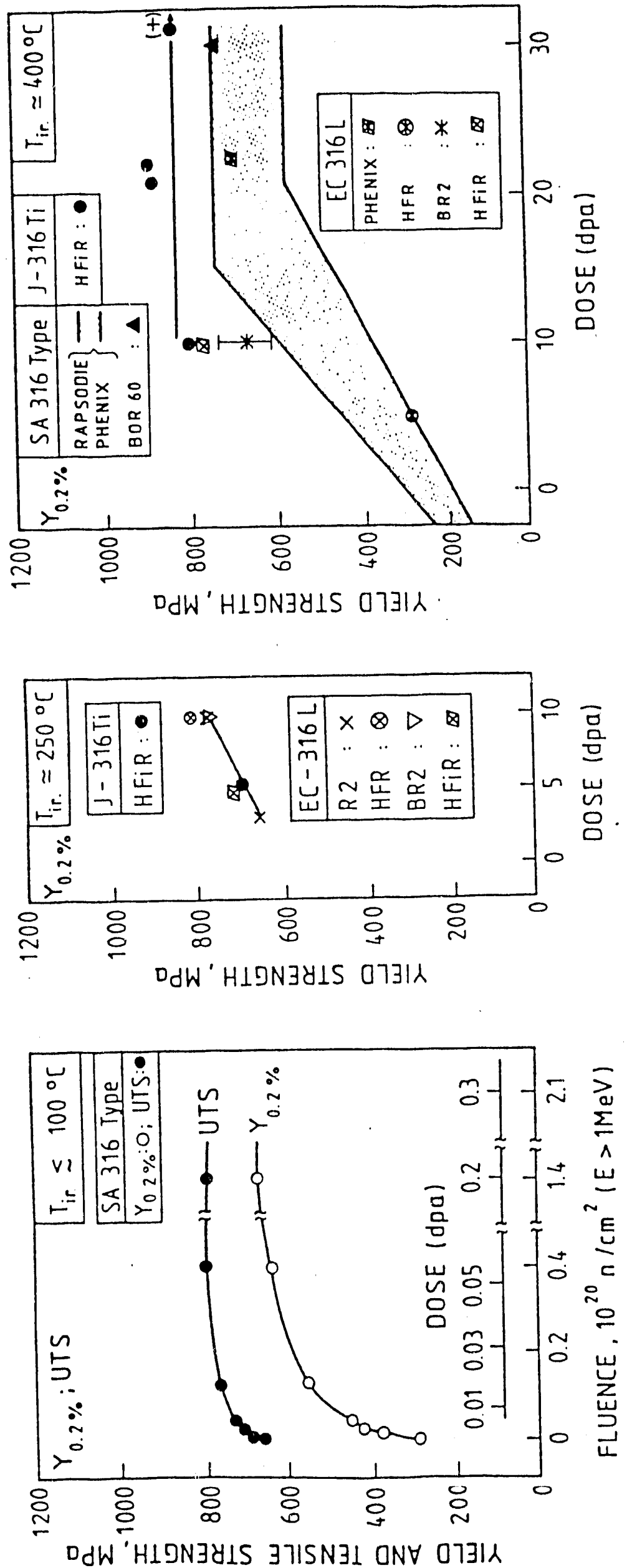
Fig. 5

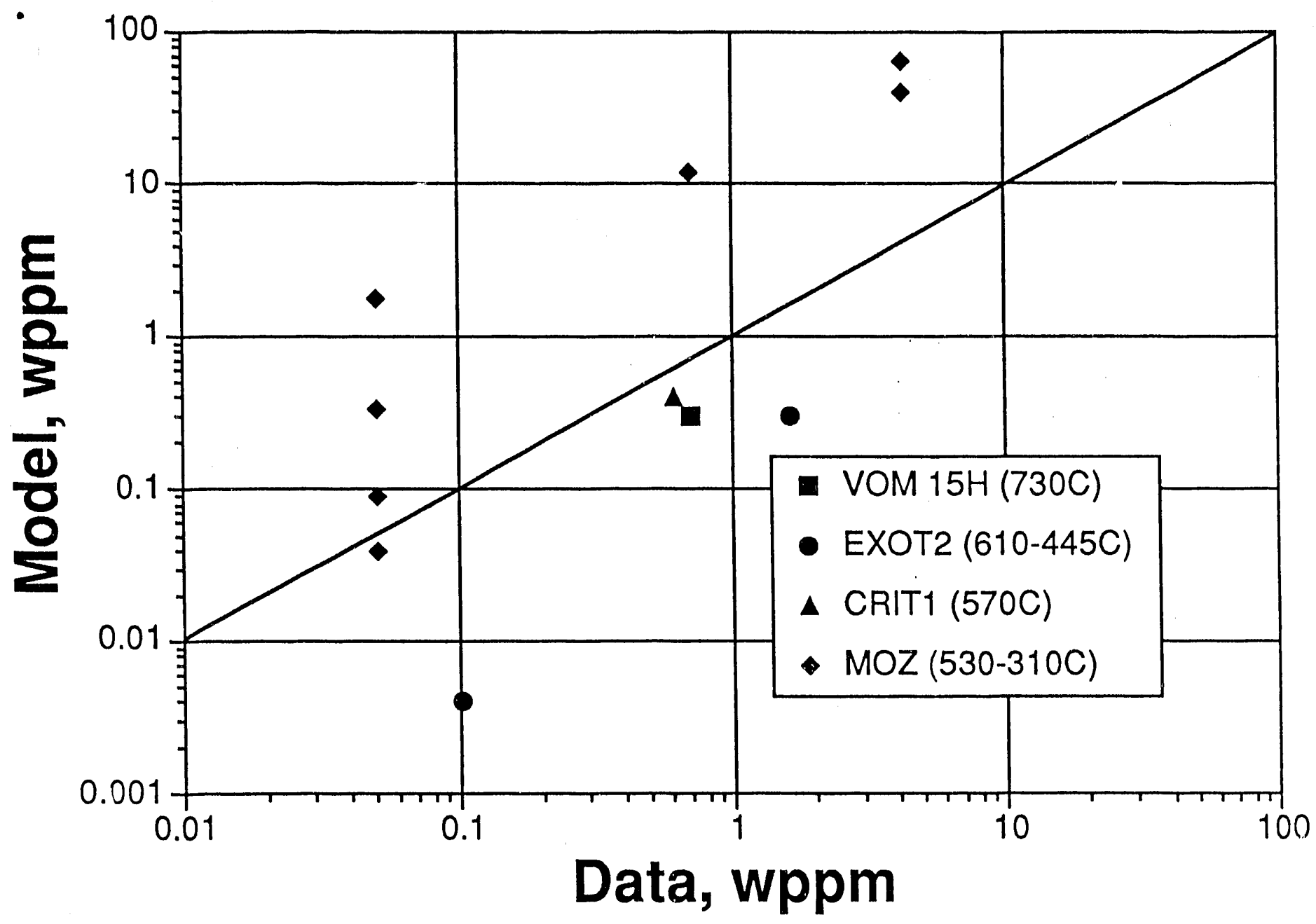


Fig.. 6

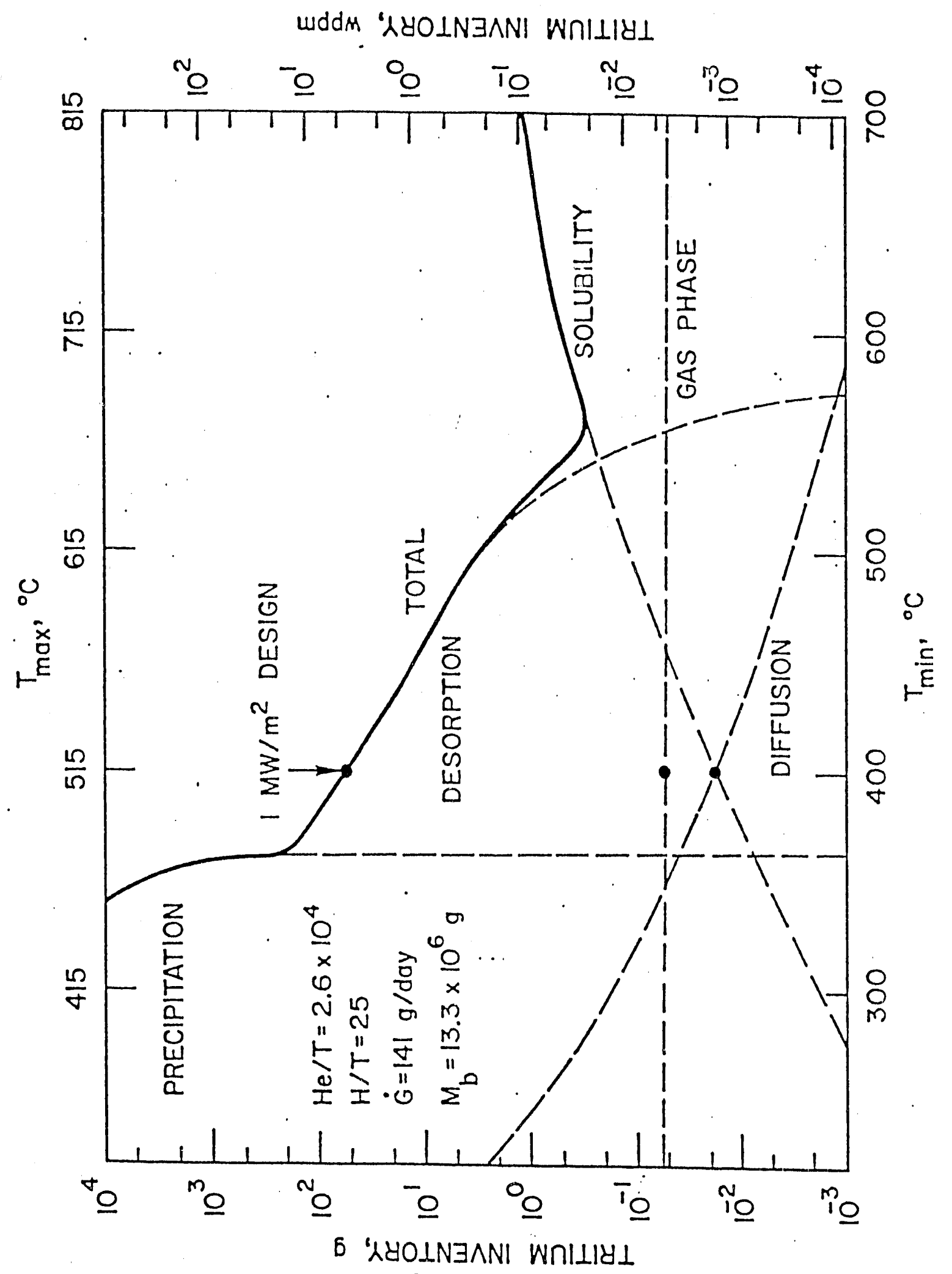


Fig. 7

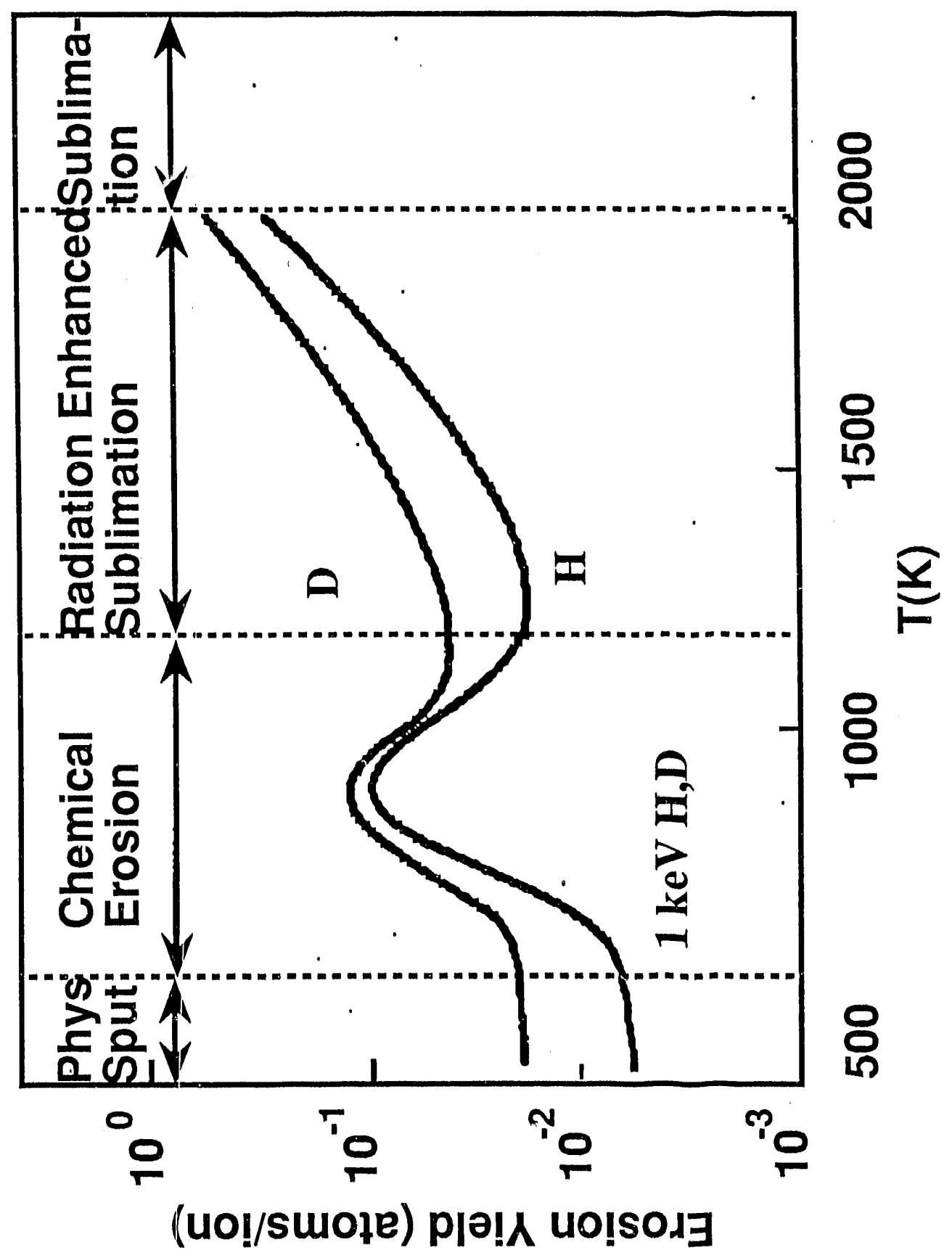


Fig. 8

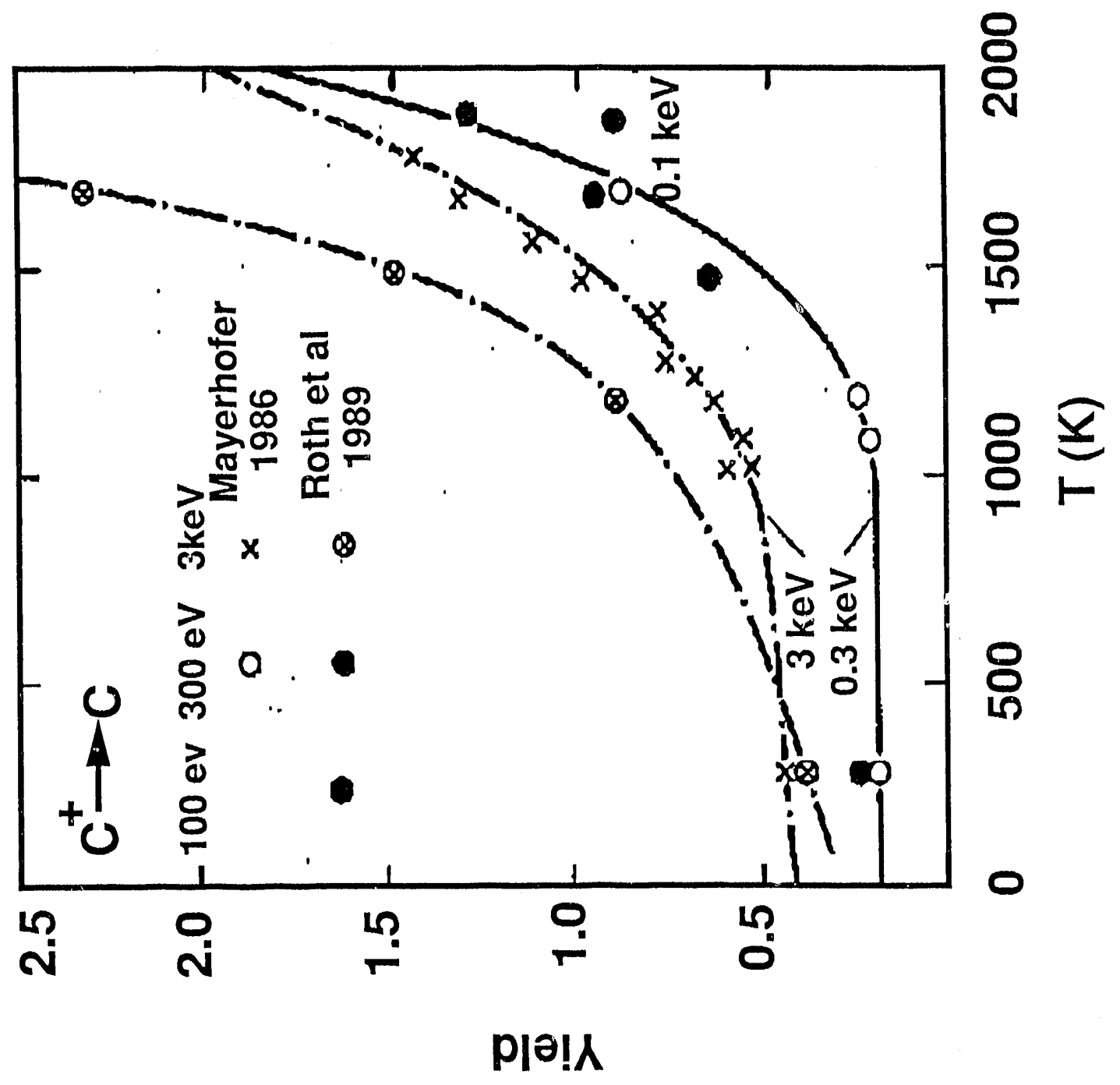


Fig. 9

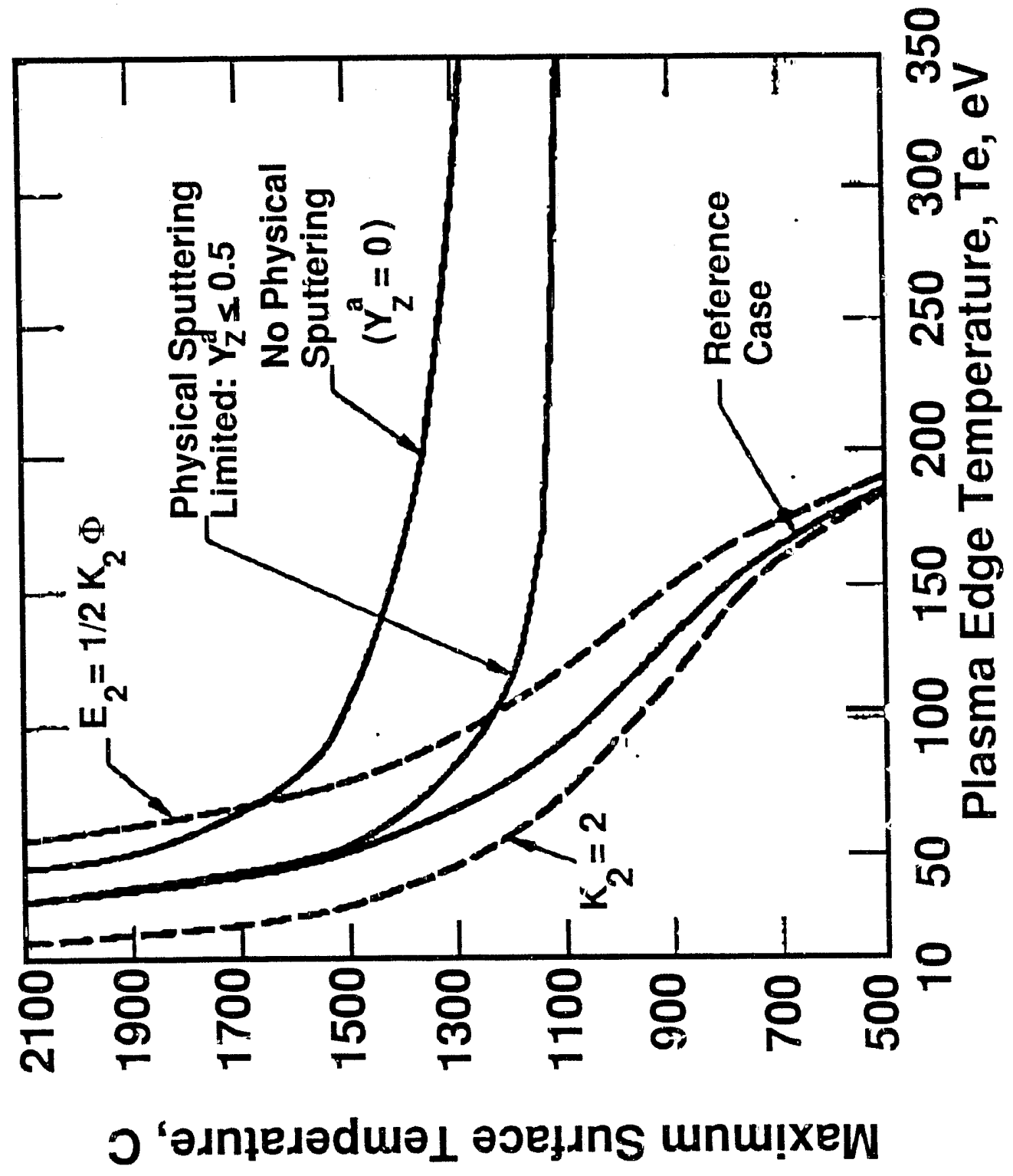




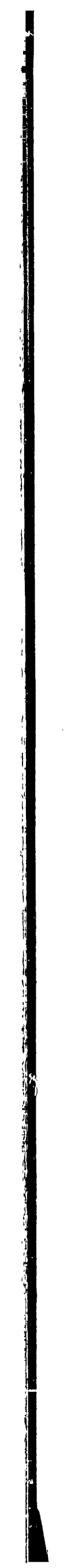

